\title{
La representación de la cultura centroamericana en el relato de viajes de Wilhem Marr'
}

\section{(The Representation of the Central American Culture in the Travel Narrative of Wilhelm Marr)}

\author{
Gustavo Camacho Guzmán²
}

Universidad Nacional, Heredia, Costa Rica

\begin{abstract}
Resumen
El artículo analiza la representación de la cultura centroamericana en el relato Viaje a Centroamérica (1863), del alemán Wilhelm Marr. El texto hace observaciones sobre la cultura, las costumbres y las tradiciones de Nicaragua y Costa Rica durante el siglo xIx, lo cual da cuenta, no solo de las condiciones culturales de ambos países, sino también de una forma de interpretar la cultura y la civilización en la cual Europa adopta una posición superior y de privilegio ante los demás países, lo cual implica una visión colonialista, utilitaria y racista en el relato.
\end{abstract}

\begin{abstract}
The article analyzes the representation of Central American culture in the story Viaje a Centroamérica (1863), by the German Wilhelm Marr. The text addresses the culture, customs and traditions of Nicaragua and Costa Rica during the nineteenth century, all of which reflect not only the cultural conditions of both countries, but also a way of interpreting culture and
\end{abstract}

1 Recibido: 19 de noviembre de 2020; aceptado: 16 de marzo de 2021. Un desarrollo más amplio y pormenorizado de estas páginas puede encontrarse en: Gustavo Alonso Camacho Guzmán, «La representación de Centroamérica en el relato de viajes de Wilhelm Marr», tesis inédita (Heredia, Universidad Nacional, 2018).

2 Escuela de Literatura y Ciencias del Lenguaje; http://orcid.org/0000-0003-2670-4594. Correo electrónico: gustavo_a_72@hotmail.com 
civilization in which Europe adopts a position of superiority and privilege over other countries. This implies a colonialist, utilitarian and racist vision in the narrative.

Palabras clave: cultura centroamericana, literatura centroamericana, colonialismo, Wilhelm Marr

Keywords: Central American culture, Central American literature, colonialism, Wilhelm Marr

Wilhelm Marr (Alemania, 1819-1904) fue un viajero de origen hamburgués que visitó Nicaragua y Costa Rica entre 1852 y 1853 . Publicó sus impresiones de viaje en el tomo Reise nach Central-Amerika (1863). Allí el autor describe de forma pormenorizada las costumbres, los ambientes y los habitantes que encuentra en su viaje por ambos países. Esta particularidad implica que el autor dejó constancia de las condiciones a partir de las cuales el viajero observa, describe y evalúa las costumbres y las prácticas comunes en la población centroamericana de la mitad del siglo XIX.

La visita de Marr a Centroamérica no es un hecho aislado. Durante el siglo XIX, el istmo fue visitado por al menos treinta alemanes que recorrieron Nicaragua y Costa Rica entre 1844 y 1899, muchos de los cuales contaban con intereses económicos o de exploración de los territorios con fines comerciales ${ }^{3}$. La exploración de tierras con fines utilitarios fue habitual en ese siglo, aunque los antecedentes se remontan a la segunda mitad del siglo XVIII ${ }^{4}$. Pratt sostiene que el sistema de clasificación de la naturaleza creado por Carl Linneo se llevó a la práctica como un intento de ordenar y controlar el mundo:

3 Göetz von Houwald, Los alemanes en Nicaragua (Managua: Fondo de Promoción Cultural del Banco de América: 1975).

4 Sobre la literatura de viajes escrita por autores de la Ilustración, Alburquerque García menciona que para esta época, el viaje fue objeto de reflexión para Bacon, Rousseau o Diderot. Así, el viaje fue visto como un elemento fundamental en la formación de los jóvenes, en razón de la necesidad de viajar con fines educativos. Para el caso de España, Alburquerque García menciona como ejemplos del género las Cartas, de Jovellanos, o algunos textos de Moratín. Luis Alburquerque García, «El relato de viajes: hitos y formas en la evolución del género». Revista de Literatura lxxvIII, 145 (enero-junio 2011): 15-34. 
«La historia natural afirmó una autoridad urbana, culta y masculina por sobre el resto del planeta», en tanto el naturalista observa, clasifica y no se adueña o apodera por la fuerza. Con todo, el acto de ver legaliza y afirma la apropiación colonial de los lugares visitados por los exploradores, principalmente europeos ${ }^{5}$. Por esta razón, es necesaria una posición desde la cual se observe el mundo por describir y representar, tal posición es la que asume la figura del veedor, es decir, el viajero que observa y describe. En el caso de los relatos sobre la colonia, el veedor corresponde con un «sujeto blanco y masculino [...] cuyos ojos imperiales pasivamente contemplan y poseen $»^{6}$. Esto último implicaría que existe un vínculo muy estrecho entre las acciones de mirar, referir y dominar.

La importancia del relato de viajes en el período decimonónico queda, de este modo, patente; en tanto los libros de viajes «crearon el orden imperial para los europeos [que se encontraban en las colonias] y les otorgaron un lugar dentro de él». Los libros de viajes insertaron a las colonias en el esquema construido por el imperio. Tales construcciones discursivas tuvieron como objetivo fomentar la idea de que las colonias y sus respectivas poblaciones de origen europeo formaban parte del proyecto planetario, esto es, de la expansión de las fronteras del imperio. A ello se unió la necesidad, por parte de la metrópoli, de imaginar y «presentar y re-presentar» las colonias y a sus habitantes, para que los europeos supieran de ellos 7 . Esto último concuerda con el afán de consignar por escrito las condiciones del territorio explorado; Pratt afirma que el relato de viajes del xix fue un escrito que buscó la fidelidad de lo visto como estrategia económica y de poder. Tal acto, propio del veedor, se llevó a cabo desde una perspectiva de superioridad frente al ambiente y los grupos humanos observados. De esta manera, el relato de viajes de Marr es una manifestación del

5 Mary Louise Pratt, Ojos imperiales. Literatura de viajes y transculturación (México, Fondo de Cultura Económica, 2010) 84, 110.

6 Pratt, 35.

7 Pratt, 24-25. 
discurso colonialista propio de tal época, en tanto busca dar cuenta de las condiciones y posibilidades existentes en Nicaragua y Costa Rica para la eventual explotación y aprovechamiento de los recursos

En el estudio de la escritura colonial sobre la periferia aparece un conjunto de elementos que permiten explicar no solo las condiciones e implicaciones del discurso, sino también el tipo de escritura que se elige para tratar sobre las colonias. Beauchesne estudia las crónicas de la época colonial (tales como los escritos de Cabeza de Vaca), así como ciertos textos contemporáneos que tratan sobre la periferia. No es casual que el discurso elija ciertas formas de enunciación en vez de otras: si el afán del colonizador es el dar fe de lo que ha visto, la crónica o el relato de viajes son modelos discursivos que permiten este tipo de enunciación. Para Beauchesne, la periferia no es uniforme, sino que dentro del continente americano (continente otro y periférico, desde la perspectiva europea) existen una serie de centros (la Nueva España y Perú, por ejemplo) y una serie de periferias (el Amazonas, en particular $)^{8}$. De esta forma, es posible relacionar el discurso de Beauchesne con una idea propia del discurso colonial, que justificó la clasificación de los pueblos en civilizados y bárbaros, y por extensión, la idea del racismo: los pueblos se hallan más o menos desarrollados según su semejanza con respecto a un modelo, indefectiblemente europeo. Así, los virreinatos de Perú y Nueva España son un centro con respecto a otros lugares del continente, pues se parecen más a Europa, aunque no sean parte de la metrópoli.

Para Beauchesne el discurso del colonialismo no es uniforme, puesto que la periferia no es única ni homogénea, sino que dentro de ella pueden existir zonas que en distintos grados se acercan o alejan del ideal europeo de civilización'. Esta idea permite explicar los

8 Kim Beauchesne, Visión periférica: marginalidad y colonialidad en las crónicas de América Latina (siglos XVI, XVII $y$ XX-XXI) (Madrid: Iberoamericana, 2013) 16.

9 Beauchesne, 20. Esta idea no es nueva, puesto que Hegel postula una tesis semejante: la Historia y los pueblos progresan en un único sentido, de ahí que algunos se hallen más desarrollados que otros. Esta aseveración aparece, por ejemplo, en Lecciones sobre la Filosofía de la Historia Universal (1837). 
mecanismos que llevan a Marr a considerar a Nicaragua de forma distinta que a Costa Rica en cuanto a su desarrollo y progreso: si la primera se encuentra sumida en la barbarie, la segunda se halla un poco más cerca del ideal que Marr lleva en mente sobre la civilización ${ }^{10}$.

A esto debe añadirse una circunstancia adicional: hacia la mitad del siglo XIX, cuando Marr viajó y escribió, aparecieron ciertas premisas sobre las razas humanas que, con el nombre de ciencia, legitimaron el colonialismo y el racismo. Al respecto, Juan Manuel Sánchez Arteaga analiza los postulados de la biología humana durante el siglo XIX ${ }^{11}$. Tras una apariencia de objetividad positivista se ocultó el prejuicio racista y la superioridad del blanco. Sánchez Arteaga resume las ideas de cinco autores de la época: Carl Vogt, Paul Broca, Thomas Huxley, Ernst Haeckel y Charles Darwin. Tales científicos apoyaron abiertamente la teoría de la superioridad e inferioridad de las razas, debate que en ocasiones estuvo de acuerdo con la poligénesis (considerar que las etnias provienen de especies diferentes). Ello explicaría «las causas últimas de los distintos ritmos en la carrera evolutiva de las razas humanas»», y por tanto, los distintos niveles de desarrollo y civilización. Para los científicos del XIX, la prueba de la superioridad e inferioridad de las razas fue tan clara que incluso aquellos que aceptaron la monogénesis estuvieron de acuerdo en reconocer las diferencias entre grupos humanos ${ }^{12}$.

Durante el siglo XIX las ciencias legitimaron como verdad empírica la superioridad del blanco sobre los demás grupos étnicos, lo cual sustentó el racismo en nombre de la biología y el naturalismo. Ello no fue exclusivo de las elites europeas; estas ideas influyeron en intelectuales ajenos a ese círculo: «Ni siquiera los poquísimos intelectuales no caucásicos [...] pudieron encontrar otro discurso socialmente legítimo para contradecir los dictámenes demenciales de la biología

10 Wilhelm Marr, Viaje a Centroamérica (San José: Editorial de la Universidad de Costa Rica, 2004) 321. En adelante, los números de página se indican en el texto entre paréntesis.

11 Juan Manuel Sánchez Arteaga, «La biología humana como ideología: el racismo biológico y las estructuras de dominación racial a fines del siglo xix». Theoria 61 (2008):107-124.

12 Sánchez Arteaga, 110-111. 
occidental sobre la jerarquía natural de las razas $\gg{ }^{13}$. Tal perspectiva de la metrópoli fue para Sánchez Arteaga ${ }^{14}$, una reelaboración de la creencia religiosa del pueblo elegido: si en la religión Dios eligió un pueblo para que fuera suyo, la ciencia proclamó que la raza blanca, europea, fue elegida por la naturaleza para civilizar el resto del mundo.

\section{Aclaración sobre el texto en estudio}

El texto analizado consiste en una traducción del original, escrito en alemán. Se trata de una traducción técnica elaborada por Irene Reinhold y publicada con introducción de Juan Carlos Solórzano por la Editorial de la Universidad de Costa Rica en 2004. Sin embargo, esta versión del texto de Marr no fue la primera en publicarse. Se han encontrado dos traducciones más de este relato de viajes: la primera recoge los capítulos XI a XV, reproducidos por Ricardo Fernández Guardia en Costa Rica en el siglo XIX. Antología de viajeros (1929). Su traducción, según Fernández Guardia, estuvo a cargo de José Dávila, filólogo del que, hasta el momento, se cuenta con escasos datos. La segunda edición del relato de Marr corresponde a los mismos capítulos, publicados en la Revista del Instituto del Café de Costa Rica, en los números 37 a 41, tomos V y VI. Estos números de la revista corresponden a los meses que van de diciembre de 1937 a marzo de 1938. Esta versión no consigna el nombre del traductor, aunque en la primera entrega se afirme que la publicación se efectúa con la autorización de Ricardo Fernández Guardia.

Al confrontar las tres versiones, muestran notable uniformidad en cuanto a la construcción discursiva y la selección del léxico, hecho que permite pensar que, en el fondo, las tres versiones del texto de Marr provienen de una primera traducción atribuible a José Dávila. Al trabajar sobre un texto traducido, es claro que en sus aspectos

13 Juan Manuel Sánchez Arteaga, «La racionalidad delirante: el racimo científico en la segunda mitad del siglo XIX» Revista de la Asociación Española de Neuropsiquiatría XXVII, 100 (2007): 384. Destacado en el original.

14 Sánchez Arteaga (2007), 395. 
formales y expresivos el discurso va a ser distinto del original, por las características propias del idioma de partida y sus diferencias respecto de la lengua de destino. Por ello, este trabajo hace hincapié en el análisis del contenido del relato y no de la forma expresiva; en específico: se analizan los tropos discursivos a los que recurre el viajero para representar a Nicaragua y Costa Rica, los cuales son subyacentes respecto de la forma de tal discurso y no cuentan con alteración alguna en la traducción. En este trabajo, se acude al estudio del régimen de representación, al contar este con un contenido cultural, compartido por una comunidad específica. Tal plano de análisis considera el examen del conjunto de imágenes culturales, literarias, y tópicos al que recurre el escritor (el viajero) para elaborar una visión del mundo centroamericano a partir de una sensibilidad marcada por el colonialismo y el racismo.

\section{La civilización y la cultura en Nicaragua}

En el relato de Wilhelm Marr, la primera mención a Centroamérica aparece cuando el viajero se encuentra en una reunión con otros alemanes. Marr expresa que una de sus intenciones es visitar los países del sur de Estados Unidos. El discurso presenta algunas ideas preconcebidas sobre el Istmo, relacionadas con el aspecto lingüístico al comparar el «mal inglés» que se hablaba en Estados Unidos con el idioma de los países hispanohablantes: «En aquellos países, de los cuales tenía ideas de naturaleza algo confusa y a los cuales pensaba viajar, se habla un español aún peor que yo no entendería» (75). En otros términos, el continente americano es lingüísticamente inferior que Norteamérica, y al mismo tiempo, que Europa. Es decir, Centroamérica cuenta con un lenguaje menos desarrollado, lo cual es una de las características que Jáuregui apunta como propias del salvaje, presente desde la antigüedad en el imaginario occidental. Este tipo de prejuicio negativo asignado a Centroamérica respecto de Europa 
o de Estados Unidos va a ser común en algunas partes del relato de viajes de Marr.

Las intenciones y los objetivos que llevan al viajero a visitar Centroamérica no se expresan claramente; parece obedecer a cuestiones políticas: el periplo se lleva a cabo meses después de que Marr enfrentara una acusación por haber criticado al gobierno francés, de ahí que su viaje pudo obedecer a la necesidad de ocultarse, de alejarse de esa situación, o incluso, de esperar a que se olvidara la controversia antes de regresar a Hamburgo (65). Al llegar al puerto de Greytown, el viajero recurre a una imagen que marca la diferencia entre el hombre europeo y el centroamericano, en tanto la disposición de los tripulantes de la primera embarcación que observa le permite asignar valores positivos y negativos a los individuos, al tiempo que ofrecer una idea sobre el tipo de habitantes de Centroamérica.

Marr afirma que tres de los tripulantes del bote eran de color "café negro», andaban desnudos y eran de cuerpos grasientos; el cuarto hombre era un blanco vestido impecablemente. Sin que el viajero exprese apreciación alguna sobre este último, a partir de la asignación de valores negativos a los primeros, es posible afirmar que sobre este último el viajero posee un concepto positivo, en virtud de su implícita identificación con el blanco.

$\mathrm{Al}$ aspecto de los nativos se añade un hecho más, la promiscuidad sexual: «[...] cuya piel heredada de su padre — digo, de su madre, pues esa gente o bien no tiene o bien tiene varios padrescontrastaba llamativamente con la ropa blanca de un hombre blanco que estaba acurrucado en el centro de la canoa» (116). La desnudez y el impulso de los instintos, implícitamente, califica a los otros como salvajes e incultos, opuestos por sí al hombre vestido que llevan en la embarcación y al viajero.

Desde el momento en que sale en piragua hacia el interior de Nicaragua, aparecen consideraciones del autor sobre la civilización centroamericana. Respecto de este tema, el viajero afirma que en Nicaragua no hay civilización, pues esta se encuentra en dos lugares en 
específico: en Europa y en Estados Unidos (135). Ello permite afirmar que en el viajero existe una tendencia implícita al eurocentrismo, y a entender la idea de cultura a la manera de Europa: ello le niega a Centroamérica la posibilidad de contar, por sí misma, con cultura y civilización propias. De esta manera, Europa y Estados Unidos (modelos de progreso y civilización para el viajero) son superiores al resto del continente americano.

Esta concepción influye, además, en la manera como se presentan el paisaje y la naturaleza. Ello queda de manifiesto al momento de describir el Lago de Nicaragua, pues no solo se trata de un paraje natural, sino que la falta de vestigios de cultura o de industria en el lago hace que este se convierta en un lugar muerto y vacío. Incluso, la ausencia de cultura es un aspecto que influye en su estado de ánimo, y ello le impide entusiasmarse por conocer, ver y describir el Istmo (153). Así, en ocasiones el relato expresa la expectativa de llegar a un lugar industrioso y desarrollado, pero tales esperanzas se desvanecen ante la pobreza y las condiciones de vida de los nicaragüenses. Es el caso de la llegada a Granada: en camino hacia la ciudad, cuenta con esperanzas de hallar una urbe similar a las de Europa, sin embargo, el aspecto de Granada muestra las condiciones de pobreza en que viven sus habitantes: así, la ciudad centroamericana se caracteriza por contar con muros de barro a medio construir o en ruinas, por ser sucia y por las edificaciones, las cuales se pueden clasificar en dos tipos: la casona de arquitectura colonial o las chozas de caña (167-168).

Empero, la situación de pobreza y de suciedad, constantes en las poblaciones que el viajero describe, contrastan con las manifestaciones culturales, los vestigios de civilizaciones antiguas o las manifestaciones de la piedad popular. En el caso de los primeros, los ídolos de las religiones autóctonas son asimilados a la cultura hispánica, de modo que se lleva a cabo un sincretismo entre la religión católica y los rastros de las religiones originarias. Ello se ejemplifica en el barrio de Jalteva ${ }^{15}$,

15 Actualmente, se conoce como Xalteva, población ubicada en León, Nicaragua. 
donde el viajero encuentra una iglesia cristiana en el lugar en donde, anteriormente se hallaba un templo autóctono. En la iglesia, a modo de cariátides del altar mayor, se encuentran «dos hombrecitos esculpidos groseramente en piedra», ídolos de las religiones originarias, y cuya función parece ser la de representar el triunfo del catolicismo sobre las religiones de los pueblos nativos, asociadas por ello a la idolatría y al paganismo (172). Sin embargo, esta funcionalidad de los ídolos indígenas dentro de una iglesia es una idea del viajero, quien incita a dar esa explicación al sacerdote a quien le preguntó al respecto.

La situación descrita pone de manifiesto no solo los procesos de evangelización llevados a cabo durante la conquista (la sustitución de un templo por otro como instrumento para que se aceptara y asimilara la religión católica), sino también la mezcla cultural que implica la combinación de dos religiones en un mismo lugar; la existencia de dos ídolos autóctonos en el altar de una iglesia católica evidencia una religión híbrida, mestiza y, si se quiere, criolla: al mismo tiempo europea e indígena. Incluso, la influencia del viajero para que el sacerdote le diera la explicación de que los ídolos representan el triunfo del cristianismo implica que el viajero impone su propia perspectiva y sus propias concepciones para explicar las características del entorno y del espacio en el que se halla.

Así, al interrogar a un centroamericano sobre las condiciones y características de la región, lo que el viajero logra es confirmar su propia visión de mundo, y anula las posibles ideas de su interlocutor; de esta manera, el diálogo que se pueda establecer entre ambos acaba siendo una repetición de lo que el europeo opina: no se trata de un diálogo, sino de un monólogo, en el cual prevalece la palabra del extranjero y su visión colonial de los otros y de sus manifestaciones culturales.

Las muestras de piedad popular presentes en la representación de Nicaragua son, principalmente, dos: el velorio de un niño y la festividad de la Inmaculada Concepción. Respecto de la primera, es notorio el carácter festivo con el que se puede tratar un aspecto que pudiera adoptar connotaciones de tristeza. La muerte es motivo de celebración y alegría 
cuando es la de un niño. Luego de describir la iglesia de Jalteva y sus ídolos de piedra, el viajero menciona una fiesta al aire libre: el baile, la conversación y demás señales de júbilo, como la presencia de fuegos artificiales, se unen en el velorio de un niño. Al igual que en la iglesia, el velorio se califica como un ritual que se encuentra a medio camino entre el catolicismo y las creencias indígenas.

Sin embargo, esta combinación de culturas y de religiones puede hallar una explicación coherente dentro de los parámetros del cristianismo, en tanto se puede creer que el niño muere sin conocer el pecado y los sufrimientos del mundo: «El buen Dios ha recibido otro ángel pequeño y moreno y el pequeño ángel de color café se ha escapado del peligro de hacerse un pecador terrestre» (172). Esta situación lleva al viajero a considerar una imagen bucólica sobre el indígena y sobre Centroamérica: el velorio concuerda con las imágenes de los relatos de viajes que se leen en Europa sobre los lugares exóticos para la concepción eurocéntrica, de modo que aparece así la imagen del buen salvaje en el relato de Marr.

Otro tipo de actividades que permiten vislumbrar las manifestaciones de la cultura nicaragüense son la celebración de la Inmaculada Concepción, llamada «María Concepción» por el viajero (211). El festejo, realizado durante la estadía del viajero en Masaya, incluye, además, un hecho esperado por el viajero con expectativa, pues corresponde con una de las actividades del mundo europeo: el teatro. La descripción de la fiesta popular inicia con una procesión: la imagen de la virgen y el canto de las letanías, elementos propios de la cristiandad, se unen en mismo conjunto con las manifestaciones no europeas:

Alrededor de la muchedumbre salvaje y fantástica [de la procesión] corrían indios y negros desnudos y medio desnudos, aullando y agitando astillas de pino encendidas, o bien se habían envuelto en pieles de vacas que estaban llenas de petardos, bombetas y varios otros fuegos artificiales que ardían y explotaban. (211) 
La cultura nicaragüense descrita en el relato no es uniforme: es una combinación de rasgos europeos (como una celebración católica y el rezo de letanías) y rasgos de culturas no europeas. A ello se une el conjunto de rituales que rodean el nacimiento, tales rituales corresponden a una cultura propia de la región, y están relacionados, además, con las prácticas referentes a la salud: «Cuando a un indio le nace un hijo [...] lo lleva a la playa (eso significa aquí, en general, al lago) y allí lo mete debajo del agua. Si la pequeña criatura, como es lógico, después tiene catarro, entonces el indio vuelve al lago solo y llama tres veces en voz alta: ‘¡Viejo del Monte, cúrame a mi hijo!'» (199-200).

A pesar de las condiciones descritas sobre la cultura, hay un aspecto sobre el cual el viajero afirma que Centroamérica es superior a Europa: el trato y el intercambio comerciales. El comercio en Nicaragua puede llevarse a cabo en completa libertad y sin prejuicio alguno sobre la vergüenza, por lo cual, el viajero considera que el país es superior a Hamburgo, puesto que en Europa, vender artículos por las calles se considera indigno de un caballero: en Europa «uno deja de valer como caballero si en caso de emergencia prefiere ganar su pan con honestidad que con estafas en guantes de cabritilla» (174-175).

Ello se afirma después de que el viajero intentara vender unas joyas y no recibió reparo alguno en que el hombre que las gentes consideraban un médico alemán vendiera alhajas por las calles. Para el viajero resulta negativo el disimulo al que se dedican ciertos grupos en Europa cuando se trata de las relaciones de comercio y las actividades lucrativas, pues desde esta perspectiva, el vender artículos de puerta en puerta no es digno de caballeros. A pesar de ello, para el viajero la actividad más practicada por los nicaragüenses es el robo, pues en Nicaragua «la artesanía honrada del bandido es la ocupación preferida de la clase baja y el hampa la de la clase alta» (179).

En cuanto a las prácticas médicas y el tratamiento de las enfermedades, el viajero, más que asegurar que se trata de la práctica cabal de la medicina, afirma que son costumbres cercanas a la curandería y 
las supersticiones. Esto se observa en el episodio sobre Granada: un sacerdote español aplica «su ipecacuana y su tártaro emético» (178) para cualquier enfermedad, hasta que llegó un médico alemán (el viajero lo llama Dr. B.), quien practica una medicina también rudimentaria, en ocasiones relacionada con la curandería y el empirismo. Incluso, se llega a considerar a Marr como otro médico alemán por haber ayudado al Dr. B. con los pacientes que este atendía:

Por la tarde recibía lecciones y pronto mi manual estuvo lleno de apuntes patológicos. Avancé pronto, pues el campo me interesaba y el dicho de Goethe «de dejarlo al final como a Dios le place», me procuró el bonete de doctor. Si un día la muerte pálida se acerca a mi lecho, podré decir con buena conciencia que no he curado a nadie hasta la muerte y que por lo menos era superior a los médicos nativos. (180; destacado en el original)

Además de que se practica una medicina muy rudimentaria, el estado de los establecimientos de salud era deplorable, en tanto no contaban con medida alguna para tratar enfermedades. Después de haberse hecho médico por la práctica empírica, el viajero describe un hospital de la región. En la descripción de ese establecimiento resalta el rechazo implícito del viajero ante las condiciones en que aquel se encuentra; por ejemplo, tal hospital es «un lugar donde en Europa no siquiera dejarían morir a un perro rabioso», en el que trabajan, no médicos, sino «hombres sanguinarios» con instrumentos de tormento y asesinato. En suma, en Granada no hay hospital sino un lugar en donde se tortura y mata a los enfermos. Por ello, la medicina no es un oficio en Nicaragua, sino la práctica de un «delito». Sin embargo, la opinión del viajero respecto de los nicaragüenses a los que debe atender como médico es negativa, en tanto les niega la categoría de humanos; cuando asistió a la amputación del pie de una anciana, el viajero consideró «si no sería crueldad con los animales tomar aquí medidas cortantes» (180-182). 
La condición de pobreza, que se generaliza a los aspectos ya apuntados, también se halla en las descripciones sobre las diferentes instancias del gobierno de Nicaragua. Es este el caso de la descripción del ministro de finanzas, las habitaciones del presidente y el ejército. El encuentro con el ministro se lleva a cabo en una tienda, casi de forma casual. El viajero entra al establecimiento, del que sale «un hombre amarillo con una chaqueta blanca y corta y un pantalón de casimir gris»), cuya apariencia dejaba ver un descuido intencional (177-178). Un hecho similar ocurre cuando Marr llega a Managua y conoce al presidente de la república. Sobre Laureano Pineda, se afirma que estaba tendido en una hamaca, en su casa de habitación, similar a las casas de clase alta del país. Sin embargo, hay un aspecto que permite pensar en el estado higiénico de la casa de Pineda: la cantidad de pulgas que firma el viajero se llevó de la casa del presidente (222-223).

Por las características anotadas para la cultura en Nicaragua, no es extraño que el viajero cuente constantemente con la expectativa y el deseo de hallar condiciones culturales y sociales similares a las de Europa, pero su deseo acaba defraudado: a los ojos del viajero, la ausencia de la civilización europea en Nicaragua era evidente y generalizada: «la falta de cultura donde todas las condiciones para tal me saltaban a la vista en un instante, me impedían el arranque del entusiasmo, después de haber pagado el tributo del asombro» (153). Por tal razón, no halla en Nicaragua las condiciones culturales que esperaba encontrar, en virtud de su eurocentrismo. De esta manera, la Centroamérica plasmada por el viajero en su relato aparece descrita como un lugar agreste, salvaje, habitado por seres incultos, y por tanto, como un lugar muerto y vacío, mientras que por oposición, Europa (Hamburgo, en especial) se califica como viva, llena de civilización, culta y refinada: «[...] los nombres que suenan tan bonitos como Granada, León, Realejo, a mí también me prometían por lo menos una copia de condiciones y confort europeos») que no llegan a concretarse (167). En la descripción de los nicaragüenses, el viajero recurre a varias de las idea apuntadas por Bartra y por Jáuregui que han servido 
para describir al salvaje desde antes de la colonización de las partes no europeas del mundo: la lengua bárbara, la distancia geográfica, el estado de desnudez, la carencia de cultura desarrollada o de un orden efectivo de gobierno (a pesar de que existe un sistema de gobierno en Nicaragua) y la primacía de los instintos son ideas que el viajero toma para describir lo que observa, pero son ideas preconcebidas, presentes en Europa desde mucho antes de la llegada del europeo a América.

\section{La civilización y la cultura en Costa Rica}

La civilización y la cultura en Costa Rica cuentan con rasgos que la acercan a la cultura europea, aunque se mantienen aspectos que el viajero asigna solamente a lo europeo o a lo centroamericano. Uno de estos que asigna a uno y no al otro es el orden y la organización: la embarcación en que el viajero se traslada desde el Realejo hasta el Golfo de Nicoya se describe como desordenada, a pesar de que el capitán del barco fuera un alemán. Ello implica una asignación de valores explícita, pues si Europa se asocia a la idea del orden, la organización y la limpieza, Centroamérica se asocia al desorden, la desorganización y la suciedad:

No obstante que el capitán era un alemán y, lo que es más, un alemán del Norte, las circunstancias propias de estos países no le permitían hacer que su barco fuera una loable excepción de la regla general; $\mathrm{y}$, aunque comparado con la mayor parte de los que se ocupaban en el servicio de cabotaje el nuestro era limpio como el oro, su aspecto horripilaba. (312)

El viajero navega por el Golfo de Nicoya y desembarca en Caldera, sitio del que elabora una descripción distinta si se la compara con las escritas por el viajero de las poblaciones nicaragüenses. Puntarenas (el nombre aparece como Punta Arenas) está emplazado en un paraje muy agradable para el viajero. Aunque la aldea presenta un aspecto ruin, la impresión que da el lugar al viajero hace que lo 
compare a algunas de las colonias de Estados Unidos en cuanto al progreso del puerto (317-318).

Parte de ese progreso se manifiesta en las relaciones comerciales de Costa Rica con Europa, sobre todo con Alemania, esto se manifiesta en la presencia de hamburgueses en el puerto de Puntarenas, así como en la impresión de limpieza y agilidad, que asocia a los «albores de la civilización»:

[...] en todas partes predominaba una índole ágil, activa y afanosa, que ofrecía el más halagüeño contraste con la tierra de la raza perdi$d a$, Nicaragua. Y cuando pasaron delante de mí tres marineros hamburgueses y escuché el bien conocido acento de nuestro idioma popular y esa francmasónica palabra de reconocimiento que emplean los hijos de Hamburgo en lejanas tierras, Hummel, me conmoví y exclamé: ¡Viva Costa Rica! (321; destacados en el original).

Sin embargo, el ordenamiento jurídico de la «tierra feliz» (320) no es del todo eficiente. Marr entró en relaciones con Hermann von Lippe, conde de Lippe, comerciante alemán acusado de estafa en los tribunales costarricenses. Las gestiones judiciales no se llevan a efecto con la eficacia necesaria, pues las disposiciones dictadas en San José no se acatan o son contradichas por las autoridades judiciales de Puntarenas: «Si el juez de comercio de San José dicta un fallo en favor del conde (como no podía menos de hacerlo conforme a las leyes del país), este fallo no se cumplía en Punta Arenas» (325). Esto implica que la organización política y jurídica del país no está del todo formada, puesto que la comunicación entre las instancias judiciales no es del todo eficaz.

Ejemplo de la falta de eficacia de las autoridades es el modo como opera una aduana entre Puntarenas y San José, así como las condiciones en que se encuentra el edificio: se trata de una «miserable choza» en la que el control aduanero para con los extranjeros es en extremo permisivo con el contrabando y el soborno por medio del alcohol, de los que conoce el encargado de revisar la mercancía que 
entra y sale del país (332). Ello muestra que las autoridades estatales, en ocasiones, son dadas a las prácticas de corrupción.

Muy distinto es lo que ocurre en la aduana de La Garita, al pie del Río Grande y en camino hacia San José: esa última no es una choza, sino que es similar a una «fortaleza» protegida del contrabando por las paredes de piedra que rodean el edificio, por el cual debe pasar la totalidad de productos que entran o salen del país (341-342). El viajero menciona que la revisión de la mercadería está a cargo del administrador general, don Salvador Gutiérrez, que no practica la corrupción ni el contrabando, salvo cuando se trata de dos altos miembros del gobierno. Esto último muestra que la mejora de las condiciones de vida y de las condiciones de construcción, así como la eficacia de la aplicación de las disposiciones legales del país mejoran cuanto se está más cerca de la capital. No obstante, las autoridades del país, en ocasiones, se dedican al contrabando cuando se trata de asuntos de su propio interés:

Este don es incorruptible hasta donde admite el carácter novohispano de la incorruptibilidad, y solo se hace de la vista gorda cuando el señor presidente Juan Rafael Mora o su cuñado el atolondrado y amable general José María Cañas, el gobernador del puerto, ordenan pasar de contrabando mercancías por su altísima cuenta propia. (343; destacado en el original).

A pesar del avance de la idea de civilización similar a la existente en Europa, existe en Puntarenas un vestigio de la cultura autóctona; en específico, con respecto a la música. El viajero describe de manera casi idílica a los indígenas que vivían cerca de Puntarenas, a lo que describe como usualmente dedicados a la música, en tanto se trata de una práctica común y reiterada, y además, los asocia con un instrumento relacionado con la cultura costarricense:

En el umbral de la puerta [de las casas de los indígenas] se veía a menudo a un hombre puesto en cuclillas repicando con dos palitos 
sobre una caja vacía, en tanto que mujeres y niños escuchaban con devoción esta música tan monótona, que dura con frecuencia hasta la noche. Algún otro tocaba danzas en la marimba, cuyo sonido se asemeja mucho al de nuestro xilófono. (326)

Respecto de la disposición de los pueblos que visita el viajero en camino hacia San José, es necesario tratar de tres: Esparza, San Mateo y Atenas. El primero se describe como lugar de poca importancia en cuanto a su desarrollo, pues los edificios son «insignificantes», sin embargo, el pueblo toma importancia por cuanto lo rodea; es decir, Esparza cobra importancia por los árboles, el paisaje y el paraje en el que se encuentra. Tal vez por esta razón lo primero que menciona el viajero sea la altitud sobre el nivel del mar y la extraordinaria fertilidad de los suelos; ello le permite establecer un contraste entre lo civilizado (las características de un edificio) y lo no civilizado (los árboles del lugar): «Hay una iglesia insignificante y mezquina [...] y tan solo resulta pintoresca por unos árboles colosales de mango que le dan sombra» (334).

No obstante, Esparza cuenta con un aspecto que el viajero contrasta con lo descrito por él en Nicaragua: en el pueblo se experimenta «una sensación de limpieza» inexistente en Nicaragua, aunque esta sensación no se compara con la del norte de Alemania. De este modo, para el viajero, aunque Costa Rica se halla más cerca de la idea de civilización con respecto a Nicaragua, estas dos últimas no se comparan con Europa, la cual viene a ser el parámetro con que el viajero mide el grado de progreso y de cultura de Centroamérica.

Marr y los alemanes con quienes emprende el camino hacia San José (Juan Knöhr y Julio Balke) pasan una noche en San Mateo, para continuar el viaje al día siguiente. A pesar de haber sido un lugar que el viajero pudiera haber observado con más detenimiento debido a esta circunstancia, la descripción de San Mateo se caracteriza por ser escueta en extremo: una altiplanicie en donde había «casas diseminadas y pequeñas haciendas» (345). No existe en de la descripción un 
elemento que defina un rasgo propio de un pueblo, como sí lo hay en Esparza, una iglesia, una plaza o un conjunto de vecinos: San Mateo se describe sin un aspecto que indique cohesión alguna, es un pueblo desperdigado.

Algo muy similar sucede con la descripción de Atenas, puesto que lo notable de este último lugar es que sirve como antesala para ingresar al centro del país, a un «Edén». El viajero sabe que ha llegado a Atenas porque menciona tres aspectos concretos: la presencia de nubes de humo, los sembradíos de maíz y plátanos y las casas que apenas pueden distinguirse (339) ${ }^{16}$. Además, Atenas sirve como punto para observar la totalidad del valle central, por lo que ofrece una vista general del centro del país: el viajero menciona los volcanes Poás, Barva, Irazú y Turrialba, las montañas de Orosí, el paso del Desengaño y la impresión de blancura de algunas iglesias o haciendas del valle (339-340).

La mención de lugares, pueblos o parajes con nombre, fuera de los mencionados, no se lleva a cabo hasta que el viajero se encuentra en San José. En el camino se encuentran muchas haciendas y el viajero cruza tres riachuelos sin saber que se trata de los que rodean la ciudad: Bermúdez, María Aguilar y Torres (344). A pesar de observar mayor animación, más construcciones y la presencia de pavimentación en las calles, los aspectos que observa no lo hacen afirmar que se encuentre en la capital:

Luego volví a ver ventanas con vidrios, muy parecidas en su forma a las de Nicaragua. A mano izquierda estaba un viejísimo cajón que, al mirarlo con más detenimiento, resultó ser una iglesia.

-Espero que pronto lleguemos a San José- dije a mi compañero-

- Hace diez minutos que estamos en la ciudad-me respondió-

16 Otro poblado que cuenta con estas mismas características es Ojo de Agua (el viajero escribe «Ojos de Agua»): solo consiste en «unas cuantas viviendas de campesinos» dispersas en media legua de extensión». Marr, 344. 
Para Marr, San José es una ciudad «en el sentido centroamericano del término» (345); no puede compararse con las condiciones de desarrollo y habitantes a las urbes europeas, pero anota que existe cierto afán de parecerse a Europa: la ciudad era relativamente limpia, contaba con ciertas construcciones de estilo europeo y las calles se identificaban con nombres; estos aspectos se suman a una sensación de «alegría y contento» en los habitantes de la ciudad. Un ejemplo de que la ciudad cuenta con un afán de imitación de lo europeo se halla en la adquisición de muebles y artefactos de hechura cosmopolita, rodeados de un ambiente poco refinado, que subraya la diferencia de condiciones:

En cuanto al gusto no lo hay ni medianamente depurado [...]. Se adquiere una cosa sin pensar que hacen falta diez más para darle el necesario realce. Es más, no se tendría empacho en poner sobre un piso de ladrillo, cerca de un diván con almohadones de terciopelo, una mesa tosca de madera, sobre la cual el dueño de la casa coloca su silla de montar [...]. (349)

Un hecho interesante en la descripción de la cultura consiste en la representación de un día de mercado en San José. Este episodio muestra un conjunto de ideas sobre las prácticas económicas comunes en la población de la capital, así como el tipo de educación que se da a los jóvenes y a los niños. El viajero describe la animación y el movimiento frente a la catedral: los habitantes dejan de ser apacibles para convertirse en mercachifles, todos los miembros de la sociedad son al mismo tiempo vendedores y compradores:

Detrás de los improvisados mostradores hay oficiales, capitanes y mayores vendiendo clavos, cortaplumas y tijeras; magistrados de la Corte Suprema expenden medias de algodón [...] Más todavía: eclesiásticos desempeñan interinamente el oficio del caballero de la vara de medir mientras este almuerza. 
Esto lo lleva a comparar el movimiento de compras y ventas con el paisaje bíblico de los mercaderes del templo: mientras en la catedral se celebra una ceremonia, los mercaderes lucran y negocian a la puerta del edificio (363). A pesar de que para el viajero el movimiento y la animación implican la actividad y la práctica mercantil, el fenómeno no deja de revestir cierta tristeza, sobre todo cuando afirma que la educación dada a los más jóvenes está en función de la artimaña comercial, el regateo y la compra y venta, cuando debería estar en función del trabajo agrícola, puesto que la principal actividad del país es la agricultura.

Esta preferencia trae consecuencias perjudiciales para la economía costarricense: dedicarse a la venta y compra de bienes reduce la cantidad de trabajadores agrícolas, esto último hará «también de los costarricenses tarde o temprano una raza perdida, salvo que un gobierno fuerte opere un cambio». Más aún, esta práctica es causa de la pérdida de productos agrícolas (se menciona el caso del café, perdido por falta de trabajadores) así como de la carestía de productos como la mantequilla y la leche: se producen solo las cantidades necesarias para el propio consumo ya que la actividad de mayor importancia es el dedicarse al mercado. De ahí que, en asuntos económicos, el viajero compare al costarricense con un judío: «La llamada Bolsa de los Judíos en Hamburgo resulta un salón comparada con la mezquindad del pequeño comercio que aquí se hace». A pesar de la actividad comercial y las consecuencias negativas para el desarrollo del país, el viajero afirma que aún se utiliza la semilla de cacao como moneda corriente en el país y que la cultura costarricense es superior a la hallada en Nicaragua (364-365).

Ejemplo de la importancia del comercio y el regateo para los habitantes de la capital es la descripción del Ministro de Hacienda y Guerra, Manuel José Carazo: el viajero describe que el ministro y su esposa atendían una venta de todo tipo de artículos, en la que se acostumbra practicar el regateo, no obstante que el talento y el conocimiento de Carazo son tales que se desperdician en asuntos de 
ese tipo: un hombre que parece un «buhonero judío» (365), aunque con el trato continuo, el ministro parece el «europeo más culto y no a un habitante de un remoto rincón de la tierra» (366). Este personaje es un ejemplo de la afición apuntada por Marr al afán de lucro y de negocio que él halla en los costarricenses: se trata de un ministro del Estado que cuenta con un negocio particular cuya finalidad es el lucro. A diferencia del mercado de San José, el que se efectúa en la plaza de Cartago cuenta con una descripción ajena al regateo y la posible estafa, se trata de una descripción más cercana a lo agrícola y lo pintoresco: el viajero menciona algunos productos que pueden encontrarse en abundancia, así como la reunión de personas de todos los grupos sociales sin grandes distinciones (indígenas, campesinos, así como hombres y mujeres de abolengo):

Figuran en él [en el mercado] los más hermosos frutos hacinados en superabundancia. Montañas de naranjas, piñas, bananos y plátanos, montones de cacao, maíz y frijoles, pieles de venado y de tigre, a la par de todo lo cual montan guardia las encantadoras muchachas campesinas de ojos negros con sus coquetos sombreros de paja, iguales a los que usan los hombres, revueltas con los indios estúpidos de Orosi y Viceita y rodeadas de dones y señoritas. (385-386; destacado en el original)

Además de lo apuntado, resulta notorio el hecho de que Marr no sea el único viajero alemán en Costa Rica: él se encuentra con que Karl Scherzer y Moritz Wagner, acompañados por un bávaro de apellido Hutzel, quienes arribaron navegando por el San Juan y el Sarapiquí. Este encuentro reviste importancia para el estudio del relato de viajes sobre Centroamérica escrito por extranjeros: no solo Marr puso por escrito su viaje, sino también Scherzer y Wagner consignaron el relato de su recorrido, aunque, según Marr, la razón del viaje de ambos era de carácter científico ${ }^{17}$ : Moritz y Wagner se dedicaban a la recolección

17 En fechas recientes, se ha efectuado la reedición en español del texto de estos dos científicos: Scherzer, Carl y Moritz Wagner. La república de Costa Rica en Centroamérica (1856). (San José: Editorial de la Universidad Estatal a Distancia, 2016). 
de plantas y animales. La referencia a estos otros dos viajeros pone de manifiesto que era deplorable la condición de las rutas y caminos del país, debido a las condiciones de pobreza de la población y el poco tránsito de extranjeros hacia el país:

De nada sirvió que un agrimensor alemán de apellido Dibowsky, natural de Königsberg, les hiciera notar la circunstancia de que dese el descubrimiento de Costa Rica no habían venido ni doscientos viajeros [...] y que la población del país es demasiado escasa y demasiado pobre para poder realizar esa obra, un dentro del espíritu americano de especulación. (367-368)

El capítulo sobre San José concluye con una referencia a las ceremonias fúnebres, a las costumbres del clero costarricense y con una descripción de las peleas de gallos, las cuales son una forma de entretenimiento popular, y sirven al viajero para conocer y describir a personas que, a la postre, fueron destacadas por la historiografía nacional. Con respecto a las honras fúnebres, el viajero apunta que los ritos suelen efectuarse acompañados por música de violines y violonchelos y no se acostumbra la utilización de ataúdes de madera, sino que se utiliza un simple sudario y unas andas para trasportar el cuerpo, el cual, al momento de inhumar, se encuentra en completa desnudez.

Por su parte, el clero cuenta con dos características muy notorias: la relajación de las costumbres y la ignorancia de los sacerdotes, además de la dedicación de estos a actividades comerciales; esto se debe a que el país es, desde la perspectiva del viajero, muy tolerante en materia de religión (369):

Aparte de su ignorancia crasa, el alto clero se compone en general de alegres y regocijados colegas que producen café o llevan a sus bueyes al mercado, como el jovial y rumboso padre Bonilla, o construyen casas y procrean hijos, como el padre Madriz, el cual, de veinticuatro frutos vivos del amor ha reconocido doce como legítimos y 
les ha hecho legados en su testamento; o, por último que buscan la felicidad en el vino, como el sediento padre Calvo. (370)

Por tales razones, Marr considera que el pueblo no hay fanatismos y no ve con malos ojos las prácticas, que en principio, están vedadas para los miembros del clero, como la procreación o el alcoholismo. La visita a una pelea de gallos, al final del capítulo dedicado a la descripción de San José, se explica por un deseo del viajero: conocer a los hombres notables de la ciudad. Este resulta ser un entretenimiento, tanto para los grupos acomodados y adinerados, como para los grupos de más modesta condición. Es en una pelea de gallos en donde el viajero conoce al presidente, Juan Rafael Mora, y al jefe del ejército, José Joaquín Mora. El presidente es descrito como un hombre socarrón que delega los asuntos de gobierno en sus ministros o en sus ayudantes, y solo se ocupa de ellos en cuento afecten su propio interés. (370).

Para el viajero, los notables de San José se dedican, principalmente, al disimulo y la astucia. Tal es el caso de Juan Rafael Mora y de José María Castro Madriz. Según el viajero, Castro Madriz estuvo exiliado después de haber dejado la presidencia: «En presencia de Mora sabía dar a su fisonomía morena y pálida los pliegues dulcemente sonrientes en que el español oculta su puñal; pero Mora [...] observa con mirada recelosa las amabilidades de Castro para con todo el mundo». Por su parte, parecen no existir diferencias de grupos sociales durante la pelea de gallos, en tanto el evento reúne a las personas de toda condición: «Reinaba la más completa igualdad. El presidente no tiene el menor escrúpulo en apostar sus pesos contra los del último peón. El juego de gallos lo absorbe todo» (371).

Pasados unos días en San José, Marr parte hacia Cartago, y posteriormente, a La Angostura, en Turrialba, para trabajar como ingeniero en el proyecto de colonización que estaba desarrollando Alexander von Bülow en ese lugar. Resulta muy notorio el hecho de que Cartago no cuente con mayor atractivo para el viajero, ni con 
edificios notables, lo único que da animación y actividad a Cartago es el día del mercado: «La antigua capital del país parece como si se estuviera perdiendo el presente bajo un gorro de dormir». En ella, habita un vecindario muy afable y cordial, lo cual contrasta con las características que el viajero otorga a los josefinos: si los primeros son honrados, corteses y amables, los segundos son personas a las que se les debe tener poca confianza, sobre todo en asuntos de negocios (379).

El viajero menciona un hecho de carácter político, al describir la manera en que se colonizó el paraje en donde se asienta Cartago: el viajero afirma que gran parte del desarrollo del lugar se debe a Braulio Carrillo, quien con proceder despótico, obligó a los indígenas y a quienes vivían en el camino de San José a Cartago con tierras, a condición de que estas fueran cultivadas con maíz; tal proceder es para el viajero un acto despótico, aunque inteligente, en tanto se está llevando el progreso, la cultura y el trabajo a tierras muy fértiles, que pueden servir para provecho del ser humano. Sin embargo, las condiciones políticas de Costa Rica fueron convulsas durante ese periodo, lo cual constituye una desgracia y una causa de atraso, desde la perspectiva del viajero, a la cual se debe agregar una característica propia de la política hispanoamericana en general: el fin de los políticos centroamericanos parece ser, por lo común, la muerte, de ahí que la política sea un ejercicio peligroso, a causa de las intrigas, maquinaciones y conjuras que pueden suscitar el gobierno de países recién formados: «Por desgracia don Braulio fue expulsado por el general Morazán [...] A Morazán lo fusilaron en una revolución y don Braulio pereció en Nicaragua [en realidad, fue asesinado en El Salvador] a manos de un asesino, como sucede habitualmente a los gobernantes novohispanos» (380-381).

De este modo, la cultura y las costumbres descritas por el viajero durante su estadía en Costa Rica acercan a este país a la idea europea de civilización: para el viajero, Costa Rica es un país a medio camino entre la civilización y lo inculto o salvaje, en tanto cuenta con una sociedad en donde habita con relativo éxito una colonia de 
inmigrantes europeos, y además, resulta ser un país en donde se llevan a cabo proyectos de colonización, como el del barón von Bülow, por causa de los posibles beneficios para el país, pues la idea por la cual se promueven la colonización e inmigración europeas es por la entrada al país de trabajadores, que harían producir la tierra aún virgen. Esta es la razón por la cual el viajero apunta de la existencia de una «conspiración» (posiblemente, tal conspiración haya sido un contrato o convenio) para atraer alemanes que pudieran establecerse en el valle central ${ }^{18}$.

\section{Conclusión}

En el ámbito ideológico, el viaje de Marr está marcado por la pretensión de superioridad racial europea. Ello explica que las descripciones de las personas estén sesgadas: para el viajero, el centroamericano resulta inferior al europeo, y por tanto, a él mismo, en tanto este se considera miembro de la sociedad civilizada, europea y superior frente a los demás pueblos y culturas. No obstante, los antecedentes de la concepción del otro como salvaje están presentes en las concepciones europeas, anteriores a la conquista de América, sobre el salvaje y el caníbal ${ }^{19}$. Bartra afirma que la idea de un hombre salvaje e inculto (el homo silvestris, homo sylvaticus o el homo agrestis) resulta muy antigua dentro de la cultura europea, en tanto se halla presente en Europa desde antes de la expansión colonial. Ello se debe a que el ideal de una civilización y una cultura también implica la definición de su opuesto, es decir, de un estado de cosas salvaje y de un hombre que se halla fuera de esa cultura ${ }^{20}$. En este sentido, el

18 Marr, 419. Algunas noticias sobre este hecho se deben a Carl Scherzer y Moritz Wagner: «En junio de 1853, un alemán residente en Costa Rica, un cierto señor Marr de Hamburgo, perdió de tal manera los estribos que hizo con el Gobierno de Costa Rica un contrato que pensándolo bien, mucho se parecía a la trata de negros africanos». Véase Scherzer y Wagner, 49.

19 Bartra, Roger. El mito del salvaje (México: Fondo de Cultura Económica, 2011) 15.

20 Bartra, 12. 
salvaje consiste de una idea aplicada «a los pueblos no europeos como una transposición de un mito [...] $\gg^{21}$.

El veedor presente en este relato muestra una serie de características muy concretas: se trata de un hombre culto, étnicamente blanco, que cuenta con la educación propia de un europeo y que posee la habilidad para comerciar, negociar y llevar a cabo proyectos que impliquen la llegada de lo que él considera la civilización a una región aún sumida en el atraso y la barbarie. En tal caso, el fin implícito de Marr al dejar constancia de su periplo sería el de contribuir con la instauración de un orden colonial simbólico, en el cual Europa se hallaría en pleno derecho de intervenir para llevar al resto del mundo un modelo de cultura y de civilización muy específico, que respondiera a sus ideales. El viajero observa Centroamérica desde la perspectiva colonial y utilitaria. Por ello, el relato de viajes oscila entre dos modalidades del discurso: al tiempo que puede tratarse de una escritura referencial y sujeta a la comprobación empírica, puede contar también con las características propias de un escrito literario, es decir, con una serie de aspectos enteramente ficcionales, tales como la exageración, la estilización, la deformación, la mitificación de ciertos aspectos, así como la legitimación discursiva de la voz del narrador.

21 Bartra, 15. 
